АДИТИВНЕ ВИРОБНИЦТВО НА ОСНОВІ СЕЛЕКТИВНОГО ЕЛЕКТРОННОПРОМЕНЕВОГО ПЛАВЛЕННЯ

Габовда О.В.

\title{
ADDITIVE MANUFACTURING ON THE BASIS OF SELECTIVE ELECTRON BEAM MELTING
}

Habovda Olga

Адитивна технологія селективного електронно-променевого плавлення є унікальною завдяки тому, що прочес відбувається при дуже високих температурах та у вакуумі, $i$ деталі з деяких матеріалів неможливо отримати за іншими адитивними технологіями. Тому автор вважає за доцільне дослідити иңю технологію та висвітлити ії основні переваги у порівнянні з технологіями селективного лазерного плавлення.

Ключові слова: Адитивне виробництво, електронно-променеве плавлення, ЕВМАгсат.

Additive manufacturing opens up new opportunities for innovative technological processes and the creation of products with completely new properties, products that cannot even be manufactured using traditional technologies. Additive Electron Beam Melting Technology is unique and has great potential, despite the fact that it is not as widespread as selective laser melting based additive technologies, but due to the fact that the process takes place at very high temperatures and in vacuum, some metals and alloys are virtually impossible to obtain by other additive technologies. In addition, electron beam melting is highly productive and more resource-efficient than laser technology. Therefore, the author considers it expedient to investigate this technology and to highlight its main advantages, having carried out a comparative analysis with the technologies of selective laser melting, since this technology is claimed for industrial use on a serial scale. R D S

Key words: Additive manufacturing, electronbeammelting, EBMArcam.

Світове виробництво стоїть на порозі кардинальних змін, не в останню чергу, завдяки розвитку адитивних технологій (AM, Additive manufacturing), переваги яких важко переоцінити. Ці технології, крім всього іншого, мають переваги 3 точки зору охорони навколишнього середовища i, зокрема, емісії парникових газів та теплового забруднення, мають величезний потенціал у справі зниження енергетичних витрат та витрат матеріалів (у 10 разів і більше) на створення самих різноманітних видів продукції, підвищення продуктивності виробництва.

Трансформація виробництва у зв'язку 3 впровадженням адитивних технологій неминуча, тому проблемами АМ плідно займаються у всьому світі кращі науковці-інженери, матеріалознавці, ведуться дослідження процесів, матеріалів, розробляються нові стандарти, методи постобробки. 3 цією метою в країнах світу, особливо країнах-лідерах, таких як США, Японія, Німеччина, Китай, Велика Британія, Італія, Франція, створюються дослідницькі інноваційні центри для просування АМ. Прикладом такого центру є America Makes - National Additive Manufacturing Innovation Institute, створений у 2012 році в США(Янгстаун, штат Огайо), який є ведучим інститутом адитивних технологій США [1].

Що стосується унікальної технології селективного електронно-променевого плавлення (EBM Arcam), вона розроблена і запатентована компанією Arcam AB у 1997році, а iii перша машина була запушена у 2002p. Також Arcam АВразом з підрозділом AР\&C, який придбала у канадської компанії Raymor Industries у 2013році, займається розробкою і виготовленням металевого порошку для своїх систем.

Мета автора - проаналізувати адитивну технологію, побудовану на методі 
селективного електронно-променевого плавлення (ЕВM, electron beam melting), висвітлити іiі переваги у порівнянні 3 технологією селективного лазерного плавлення (SLM, selectivelasermelting), а також сфери їі застосування.

Головна тенденція розвитку адитивного виробництва - зосередження його на виготовленні металевих виробів. Такі компанії, як DMG MORI (німецько-японська),Siemens (німецька), Хerox (американська) розширили свої позиції завдяки купівлі підприємств 3D друку на металі. Американський концерн General Electric Co (GE) придбав дві європейські компанії, що спеціалізуються на AM з металами: німецьку SLM Solutions Group AG (лазерні машини) та шведську Arcam AB (EBM - машини). 32018 року підрозділ концерну General Electric - GE Additive Arcam EBM дислокується в Гетеборзі.

У грудні 2019 року GE Additive Arcam EBM презентувала свою останню модель Arcam EBM Spectra L (Мал.1, Таблиця1) на ведучій Міжнародній виставці по адитивному виробництву і інтелектуальному промисловому виробництву наступного покоління Formnext2019 (Німеччина).
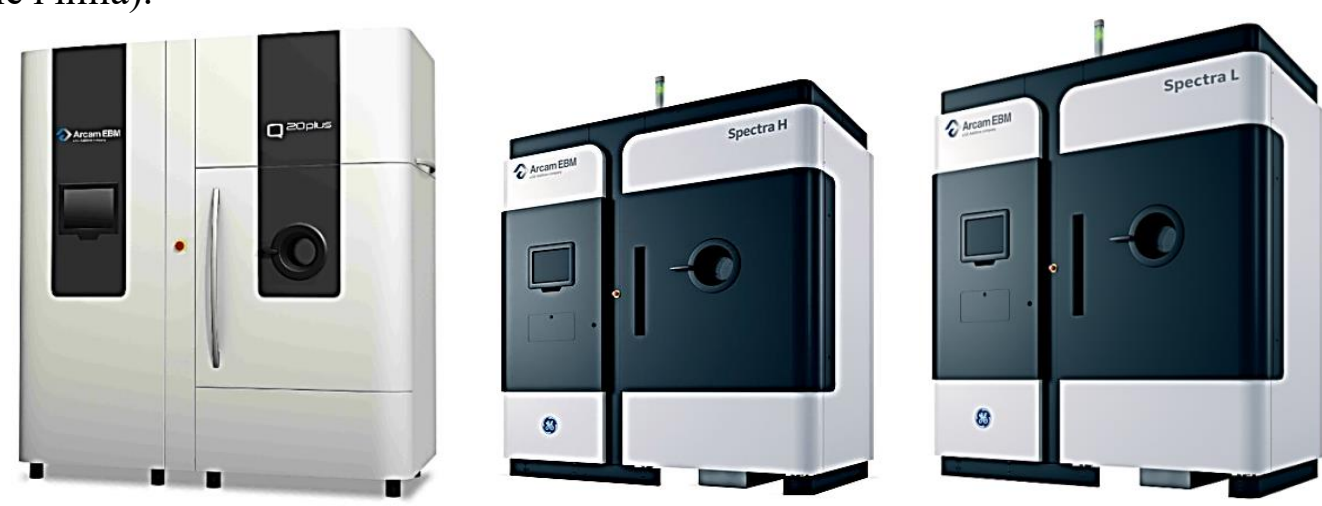

Мал. 1. Промислові машини Arcam EBM:

a) Arcam EBM Q20plus (2016p. випуску); в) Arcam EBM Spectra H (2018p. випуску);

в) Arcam EBM Spectra L (2019p.випуску).

Таблиця 1.

Основні технічні характеристики машин Arcam EBM[2-4]

\begin{tabular}{|l|l|l|l|}
\hline Модель машини & $\begin{array}{l}\text { Максимальна потужність } \\
\text { променю, kW }\end{array}$ & $\begin{array}{l}\text { Максимальний } \\
\text { розмір зборки, мм }\end{array}$ & $\begin{array}{l}\text { Типова температура } \\
\text { процесу, }{ }^{\circ} \mathrm{C}\end{array}$ \\
\hline Arcam EBM Q20plus & 3,0 & $350 \times 380 \times 380$ & - \\
\hline Arcam EBM Spectra H & 6,0 & $250 \times 430(\varnothing \times \mathrm{H})$ & $600-1100$ \\
\hline Arcam EBM Spectra L & 4,5 & $350 \times 430(\varnothing \times \mathrm{H})$ & 700 \\
\hline
\end{tabular}

Технологія ЕВМ використовує електронний промінь, створюваний електронною гарматою (Мал.2). Електронний пучок витягує електрони з вольфрамової нитки у вакуумі $\mathrm{i}$ прискорює їх проеціювання на шар металевого порошку, викладеного на будівельній плиті машини. Швидкість відхилення електронного пучка досягає $10000 \mathrm{M} / \mathrm{c}$ без будь-якої інерції. Ці електрони селективно плавлять порошок, таким чином пошарово «вирощується» деталь. Шар порошку попередньо нагрівається розфокусованим променем, який декілька разів сканує поверхню шару порошку, щоб встановити температуру попереднього нагріву. В залежності від матеріалу температура варіюється від $300^{\circ} \mathrm{C}$ для чистої міді до $1100^{\circ} \mathrm{C}$ для твердих сплавів. Це важлива перевага EBM у порівнянні з SLM, оскільки порошковий шар не тільки $\epsilon$ опорою для наступних шарів, але також має високу механічну стійкість завдяки незначному початковому спіканню на етапі попереднього нагрівання. Через незначне спікання частинок під час попереднього нагрівання гарантується ще й достатня електропровідність шару[5].

Гарячий процес дозволяє виготовляти деталі з високою щільністю без остаточного 
напруження з мікроструктурою матеріалу, вільною від мартенситних структур.

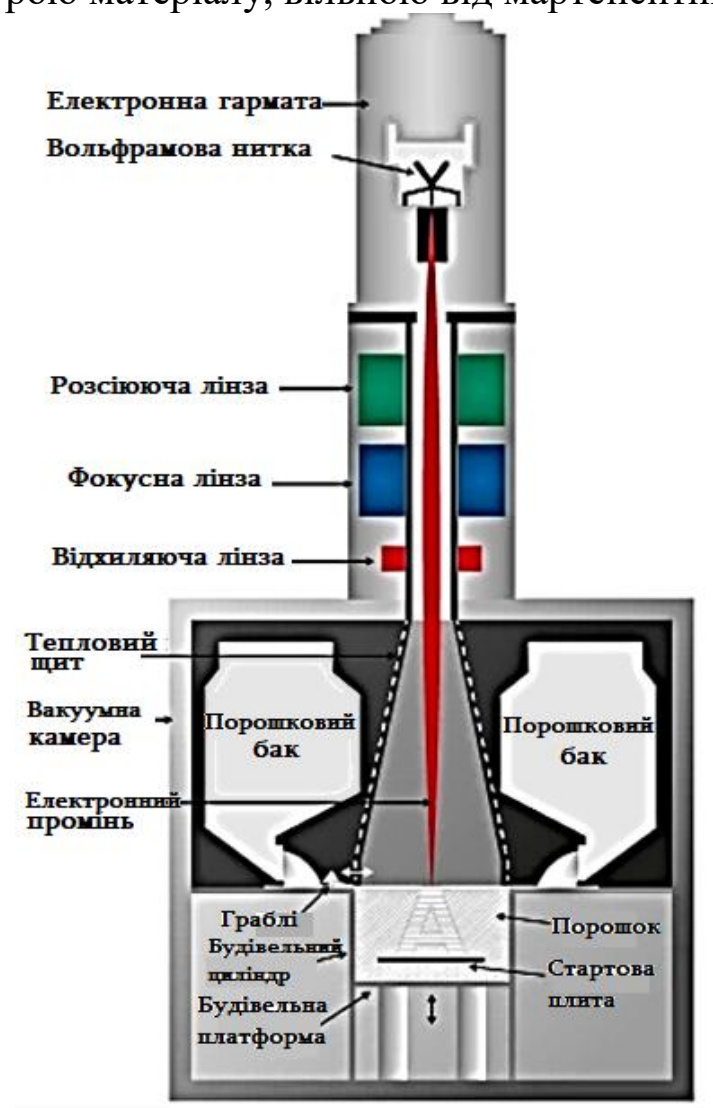

Мал. 2. Схема процесу вирощування деталі за технологією ЕВМ (Arcam EBM Spectra H)

Процес електронно-променевого плавлення відбувається у вакуумній камері (базовий тиск $-5 \cdot 10^{-4}$ мбар) для забезпечення чистого і контрольованого середовища збірки. Це також запобігає окисленню порошку при нагріванні. Вакуумне виробництво є важливим аспектом процесу ЕВМ, оскільки воно підтримує хімічну специфікацію будівельного матеріалу.

Хоча на даний час шорсткість поверхонь деталей, виготовлених EBM, вища у порівнянні з лазерними технологіями, що пояснюється розміром плями електронного пучка в зоні розплаву ( $\min 0,10 \mathrm{Mm}$ ),який перевищує розмір лазерного променю ( $\min 0,05 \mathrm{Mm}$ ), технологія ЕВМ має багато переваг, що створює їй домінуюче положення в сфері виробництва титанових протезів, імплантів та іншої медичної продукції, а також в аерокосмічній галузі та автомобілебудуванні. До того ж, ЕВМ забезпечує прийнятну точність побудови $- \pm 0,10 \ldots 0,15 \mathrm{Mм}$.

Дослідження, які проводилися незалежними експертами 3 метою порівняння виробничих затрат машини EBM Arcam з декількома лазерними, підтвердили суттєву економічну перевагу електронно-променевого плавлення при виготовленні однакових деталей 3 титану Тi64. Щодо продуктивності, то EBM - машини виробляють $60-80 \mathrm{~cm}^{3} /$ год проти $4-20 \mathrm{~cm}^{3} /$ год у аналогічних за розмірами лазерних машин. Таким чином, висока продуктивність та менші витрати стимулюють перехід 3 традиційних технологій металообробки до серійного виробництва, зокрема й за технологією ЕВМ[6].

Технологія ЕВМ підходить для унікальних, універсальних матеріалів і залишається єдиною комерційно доступною технологією для адитивного виробництва деталей 3 металів $\mathrm{i}$ сплавів, схильних до розтріскування, адже високий вміст вуглецю, наприклад, в інструментальних сталях, унеможливлює адитивне виробництво інструменту лазерним плавленням у зв'язку з низкою температурою цього процесу. Саме тому шведська компанія VBN Components AB 3 виробництва інноваційних матеріалів, зокрема, зносостійких та жаростійких металів та сплавів, а також ріжучого інструменту та інших зносостійких деталей тісно співпрацює з GE Additive Arcam EBM. 
3 VBN-матеріалів найбільш вражаючими є запатентовані останнім часом матеріали: Vibenite® 290 (2017p.)- сталь 3 твердістю 68-72 HRC (найтвердіший у світі комерційно доступний тип сталі) i Vibenite® 480 (2018p.)(отримав нагороду MM Maschinen Markt на виставці ЕМО в Ганновері у вересні 2019році) - гібридний карбід, який поєднує ударну міцність швидкорізальних сталей з жаростійкістю цементованих карбідів. Його твердість $\approx 66$ HRC[7-8].

У кінці 2019 року GE Additive Arcam EBM заявила про вихід на промисловий випуск деталей з чистої міді протягом 2020 року (мал.3).

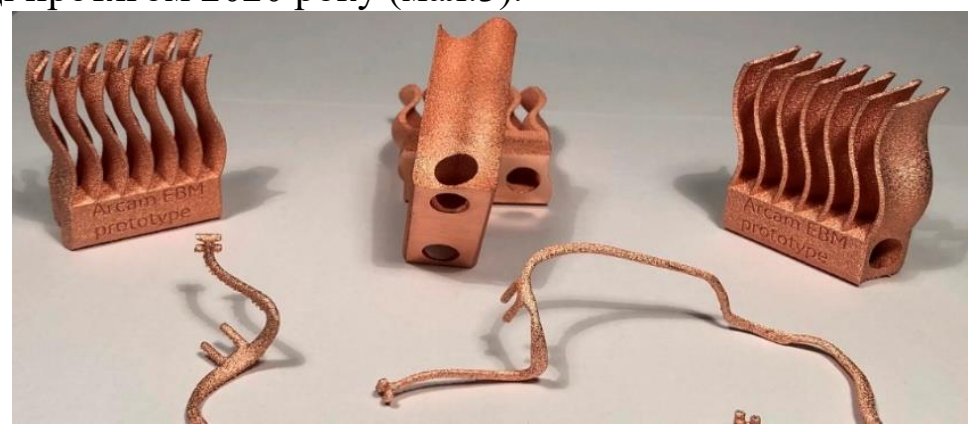

Мал.3. Мідні вироби за технологією Arcam ЕВМ

Здатність міді поглинати енергію залежить від довжини хвилі джерела енергії. Чиста мідь поглинає 80\% енергії електронного променю, в порівнянні 3 2\% енергії червоного лазерного променю, що дає значні переваги у продуктивності EBM - машин у порівнянні 3 лазерними. Крім того, вакуумне середовище, в якому працює ЕВМ, зводить до мінімуму поглинання кисню в міді, що дозволяє отримувати мідь 3 високою провідністю. Кисень знижує провідність міді, а також деталь стає більш крихкою.

Постачальники лазерних технологій при виробництві мідних виробів для поліпшення лазерного поглинання легують порошки, що погіршує чистоту міді, адже й iii електропровідність [9].

В результаті дослідження технології селективного електронно-променевого випромінювання та порівняльного аналізу з технологіями селективного лазерного плавлення автор прийшла до наступних висновків:

1. ЕВМ $є$ унікальною технологією для виготовлення деталей високої твердості, схильних до розтріскування, завдяки наявності потрібних високих температур плавлення $\left(600-1100^{\circ} \mathrm{C}\right)$ в робочому процесі.

2. Технологія ЕВМ забезпечує виготовлення виробів з чистої міді без необхідності введення легуючих елементів у порошок задля збільшення поглинання міддю енергії лазерного променю, адже мідь поглинає $80 \%$ енергії електронного променю і порівнянні з $2 \%$ енергії лазерного променю.

3. Додаткова перевага - можливість сканування шару порошку електронним пучком в розфокусованому режимі при високих швидкостях його відхилення для попереднього нагрівання, яка дозволяє отримати високий вхід енергії без повного розплавлення порошку, що до мінімуму зменшує залишкові напруги, особливо в товстостінних деталях.

4. Технологія ЕВМ є більш продуктивною і менш витратною щодо матеріалу у порівнянні з лазерними технологіями, що робить їі більш придатною до серійного випуску виробів.

\section{Список використаних джерел}

1. America Makes [Електронний ресурс]. - Режим доступу: https://www.americamakes.us.

2. Arcam EBM Q20plus v2.0 [Електронний ресурс]. - 2020. - Режим доступу: https://www.ge.com/additive/sites/default/files/2020-01/EBM_Q20Plus_ DS_EN_US_1_v1.pdf. 
3. GE Additive Unveils Arcam EBM Spectra H [Електронний ресурс]. - 2018. - Режим доступу:https://www.pressreleasefinder.com/prdocs/2018GEADPR008EN0418GE Additive Unveils Arcam_EBM_Spectra_H.pdf.

4. Arcam EBM Spectra L v1.0 [Електронний ресурс]. - 2019. - Режим доступу: https://www.pressreleasefinder.com/prdocs/2019/GE_Additive_EBM_Spectra_L_tech_spec _-_November_2019.pdf.

5. Matthias Mark, Matthias Lodes, Martin Franke, Carolin Körner. Additive manufacturing using selective electron beam melting [Електронний ресурс]. - 2017. - Режим доступу: https://www.researchgate.net/profile/Matthias_Markl/publication/317955281_Additive_man ufacturing_using_selective_electron_beam_melting/links/595368460f7e9b329242af32/Addit ive-manufacturing-using-selective-electron-beam-melting.pdf.

6. ЕВM manufacturing advantages: High productivity and lower costhttps [Електронний pecypc]. - 2019. - Режим доступу: https://www.ge.com/additive/ebm.

7. VBN Components exhibits 3D printed cemented carbide at EMO Hannover [Електронний pecypc]. - 2019. - Режим доступу: https://vbncomponents.se/category/news/.

8. Additive Manufacturing VBN'speciality [Електронний ресурс]. - 2019. - Режим доступу: https://pub.bergsmannen.se/2c54c5b6-638b-44f0-b113-f0e81 aff4de2\#page=52.

9. GE Additive Arcam EBM launches D-material support for Pure Copper and Highly Alloyed Tool Steel [Електронний pecypc]. - 2019. - Режим доступу: https://www.ge.com/additive/press-releases/ge-additive-arcam-ebm-launches-d-materialsupport-pure-copper-and-highly-alloyed.

\section{References}

1. “America Makes". https://www.americamakes.us.

2. “Arcam EBM Q20plus v2.0”. 2020. https://www.ge.com/additive/ sites/default/files/202001/EBM_Q20Plus_DS_EN_US_1_v1.pdf.

3. "GE Additive Unveils Arcam EBM Spectra H”. 2018. https://www.pressreleasefinder.com/prdocs/2018GEADPR008EN0418GE_Additive_Unveil s_Arcam_EBM_Spectra_H.pdf.

4. “Arcam EBM Spectra L v1.0”. 2019. https://www.pressreleasefinder.com/ prdocs/2019/GE_Additive_EBM_Spectra_L_tech_spec_-_November_2019.pdf.

5. Mark, Matthias, Lodes, Matthias, Franke,Martin, Körner, Carolin. 2017. "Additive manufacturing using selective electron beam melting". https://www.researchgate.net/profile/Matthias_Markl/publication/317955281_Additive_man ufacturing_using_selective_electron_beam_melting/links/595368460f7e9b329242af32/Addit ive-manufacturing-using-selective-electron-beam-melting.pdf.

6. "EBM manufacturing advantages: High productivity and lower costhttps". 2019. https://www.ge.com/additive/ebm/.

7. "VBN Components exhibits 3D printed cemented carbide at EMO Hannover". 2019. https://vbncomponents.se/category/news/.

8. “Additive Manufacturing VBN'speciality". 2019. https://pub.bergsmannen.se/2c54c5b6638b-44f0-b113-f0e81aff4de2\#page=52.

9. "GE Additive Arcam EBM launches D-material support for Pure Copper and Highly Alloyed Tool Steel". 2019. https://www.ge.com/additive/press-releases/ge-additive-arcamebm-launches-d-material-support-pure-copper-and-highly-alloyed. 